\title{
INFLUÊNCIA DA REUTILIZAÇÃO DO PEQUI (Caryocar brasiliense) NO RENDIMENTO DA EXTRAÇÃO DE ÓLEO
}

\author{
M.C.P de ASSIS ${ }^{3}$, T.C.S.BARBALHO ${ }^{3}$, I.L.LUCENA ${ }^{1}$, I.M.JALES ${ }^{2}$, A.D.T.PINHEIRO ${ }^{1}$ \\ ${ }^{1}$ Universidade Federal Rural do Semiárido, Departamento de Agrotecnologia e Ciências \\ Sociais \\ 2 Universidade Federal Rural do Semiárido, Laboratório de Engenharia Química \\ 3 Universidade Federal Rural do Semiárido, Departamento de Agrotecnologia e Ciências \\ Sociais \\ E-mail para contato: alvaro_eq@hotmail.com
}

\begin{abstract}
RESUMO - O objetivo deste trabalho foi avaliar a influência da reutilização do pequi (Caryocar brasiliense) no rendimento da extração de óleo. Para tanto, a polpa e a amêndoa foram separadamente trituradas e posteriormente secas em estufa. A extração dos lipídeos foi realizada pelo método sonoquímico. Os cálculos de rendimento mostraram resultados em torno de $27,36 \%$ para a primeira extração da polpa e $26,89 \%$ para a da amêndoa, enquanto que a reutilização dessas amostras apresentou decréscimo significativo. Cada amostra foi reutilizada três vezes, contudo somente a primeira reutilização da polpa demonstrou viabilidade com um rendimento de $16,73 \%$. Para as demais reutilizações, o rendimento caiu para menos de $10 \%$. Desempenho semelhante foi observado para a reutilização da amêndoa, onde o rendimento da primeira reutilização foi em torno de $26,89 \%$ e o rendimento dos demais caiu para menos de $10 \%$. Dessa forma, pode-se concluir que o reciclo mostrou-se eficiente, se aplicado apenas em uma etapa.
\end{abstract}

\section{Introdução}

O pequi (Caryocar brasiliense) é um fruto oriundo do pequizeiro, palmeira nativa do cerrado encontrada principalmente nos estados de Minas Gerais, Goiás, Mato Grosso e Mato Grosso do Sul. O plantio de sementes se dá na estação chuvosa e sua safra ocorre entre os meses de novembro e fevereiro (LORENZI, 2000). Semelhante aos frutos do dendezeiro e da macaúbeira, o pequi contém óleo na polpa e na amêndoa. Segundo Mariano (2008) o óleo da polpa é rico em carotenóides ácidos graxos monoinsaturados constituídos em sua maior parte por ácido oléico e palmítico, já o óleo da amêndoa apresenta-se de forma mais insaturada, sendo assim mais líquido que os demais óleos extraídos das palmáceas citadas.

A aplicação do óleo do pequi também está sendo difundida na indústria cosmética (DEUS, 2008), por apresentar características químicas antioxidantes que são responsáveis por combater os radicais livres que provocam a oxidação das células, acarretando o envelhecimento. 
$\mathrm{Na}$ medicina, o óleo da polpa pode ser usado como tonificante, atuando contra bronquites, gripes, resfriados e no controle de tumores. Os frutos são ricos em vitamina A e C, tiamina, proteínas e sais minerais, sendo o óleo de pequi utilizado na medicina popular para sanar problemas oftalmológicos relacionados à deficiência de vitamina $\mathrm{A}$, uma vez que a planta apresenta altíssimo teor de carotenóides (BRANDÃO et al., 2002; RIBEIRO, 1996). De acordo com Fraga (2012) óleo de pequi também pode ser aplicado como um forte agente terapêutico para portadores de lúpus e diabetes.

Muitas formas de extração de óleo são conhecidas e utilizadas atualmente, como por exemplo, extração por prensagem, por solvente, enzimática, entre outras, porém, estudos recentes mostram resultados positivos para o uso do ultrassom no auxílio dessas extrações quando realizadas por rota química. Matos et al (2009) estudaram a extração do óleo da borra de café utilizando o ultrassom e registraram um rendimento de $11,21 \%$ quando utilizaram hexano e de 7,53\% ao utilizar o etanol, sendo que, Figueiredo (2011) obteve um rendimento de $12,1 \%$ ao realizar o mesmo estudo porém em condições diferentes. Resultados bastante expressivos foram obtidos quando Sganzerla et al (2009) utilizou o ultrassom para extração de óleo das amêndoas de frutos de butiá (Butia capitata e Butia eriosphata) chegando a um rendimento de 56,48\% e Dantas et al (2010) também estudaram a extração de óleo de microalgas utilizando o ultrassom com diferentes tipos de solventes, sendo o metanol o que teve maior rendimento.

Diante do exposto, objetivou-se com este trabalho avaliar a influência da reutilização do pequi no rendimento da extração de óleo.

\section{Materiais e Métodos}

Os experimentos foram realizados no Laboratório de Química Orgânica da Universidade Federal Rural do Semiárido. A matéria-prima utilizada neste trabalho foi o pequi procedente do Crato-CE, sendo o mesmo triturado, tanto a polpa quanto a amêndoa, porém, separadamente, e posteriormente seco em uma estufa (Tecnal TE-394/1) com circulação de ar a $40^{\circ} \mathrm{C}$ por 24 horas. O solvente utilizado para a extração do óleo foi o álcool etílico P.A. (Synth).

Inicialmente, foi adotada uma base de calculo de $30 \mathrm{~g}$ de farelo para a polpa e amêndoa do pequi, Os $30 \mathrm{~g}$ foram inseridos dentro de um béquer de $600 \mathrm{ml}$ com um volume de etanol na proporção 6:1 etanol/farelo previamente estabelecida seguindo a metodologia proposta por Barbalho (2012).

Em seguida, colocou-se o béquer no banho ultrassônico (Unique Ultracleaner 1400) com freqüência de $40 \mathrm{kHz}$ e uma temperatura média de $60^{\circ} \mathrm{C}$, interligado ao banho termostático (Biothec) para que a temperatura de $60^{\circ} \mathrm{C}$ fosse constante, como proposto por Araújo (2013). Cada amostra permaneceu em banho ultrassônico por 3 horas. Posteriormente, o sache foi retirado do béquer e a mistura etanol/óleo foi transferida para um evaporador rotativo (Biothec BT 351) a uma temperatura de $90^{\circ} \mathrm{C}$ interligado a um banho termostático (Biothec) com uma temperatura de $5^{\circ} \mathrm{C}$, e a uma bomba a vácuo (Primar $141 \mathrm{CC} 019$ 2VC) para separar o etanol do óleo.

Para o cálculo do rendimento do óleo nas extrações, inicialmente pesou-se o balão ainda vazio em seguida inserimos a mistura etanol/óleo nele, somente depois disto o balão foi levado ao evaporador. Uma vez evaporado todo o etanol que havia no balão o mesmo foi 
pesado novamente. Tomando o rendimento como uma variável dependente, pode-se calculálo a partir da Equação 1.

$$
\text { Rendimento }(\%)=\frac{\text { Óleo presente no balão }}{\text { Peso inicial do Pequi }}
$$

\section{Resultados e discussões}

Os resultados obtidos para o rendimento da extração demonstraram uma média de valores em torno de $27,34 \%$ para a primeira extração da polpa, conforme observado na Figura 1. Resultado diferente foi obtido por Barbalho (2012), que estudando o rendimento da polpa do pequi utilizando a mesma razão mássica e o mesmo tempo de extração encontrou valor de $12,45 \%$ para a polpa. A diferença entre estes valores de rendimento pode ser explicada pelo fato de que no estudo de Barbalho (2012), a temperatura média utilizada para a extração foi em torno de $30^{\circ} \mathrm{C}$, e no presente trabalho foi de $60^{\circ} \mathrm{C}$, provando assim a influência positiva do aumento da temperatura no rendimento.

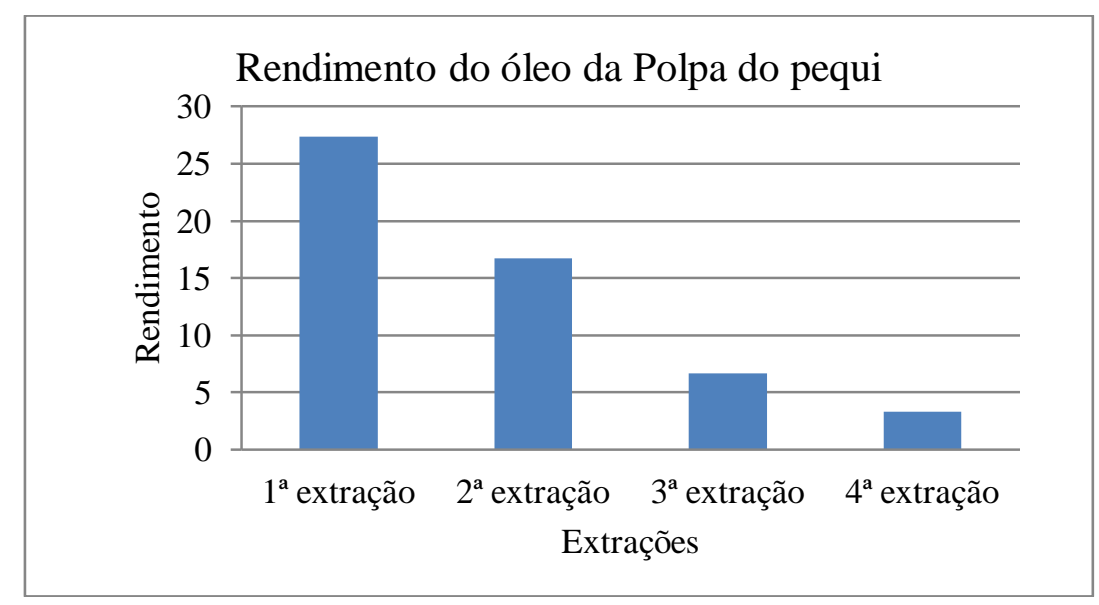

Figura 1 - Rendimento do óleo da Polpa do pequi.

Resultado próximo ao encontrado neste estudo foi obtido por Araújo (2013), a qual estudou o rendimento da extração do óleo do pequi utilizando o método de ultrassom e as mesmas condições operacionais mantidas neste trabalho, obtendo o mesmo rendimento em torno de 31,96\% para a polpa. Este resultado pode ser explicado pelo fato de que quando é aplicada uma maior temperatura na extração do óleo é gerado um maior grau de agitação das moléculas fazendo com que o processo de extração seja mais eficaz com um maior rendimento do óleo extraído.

Ao se reutilizar a amostra da polpa do pequi para a extração de óleo, observou-se um decréscimo significativo no rendimento da extração, com valores médios de 16,73\%, 6,73\%, $3,30 \%$, para a segunda, terceira e quarta extração da amostra, respectivamente (Figura 1). 
Já com relação à amêndoa, os resultados obtidos para o rendimento da primeira extração demostraram uma média de valores em torno de 26,89\%. Foi possível perceber um decréscimo, tão significativo quanto o da polpa no rendimento da extração, quando reutilizouse a amostra, possuindo valores médios de 9,54\%,5,16\%, e 3,61\%, para a segunda, terceira e quarta extração da amostra, respectivamente, conforme mostra a Figura 2.

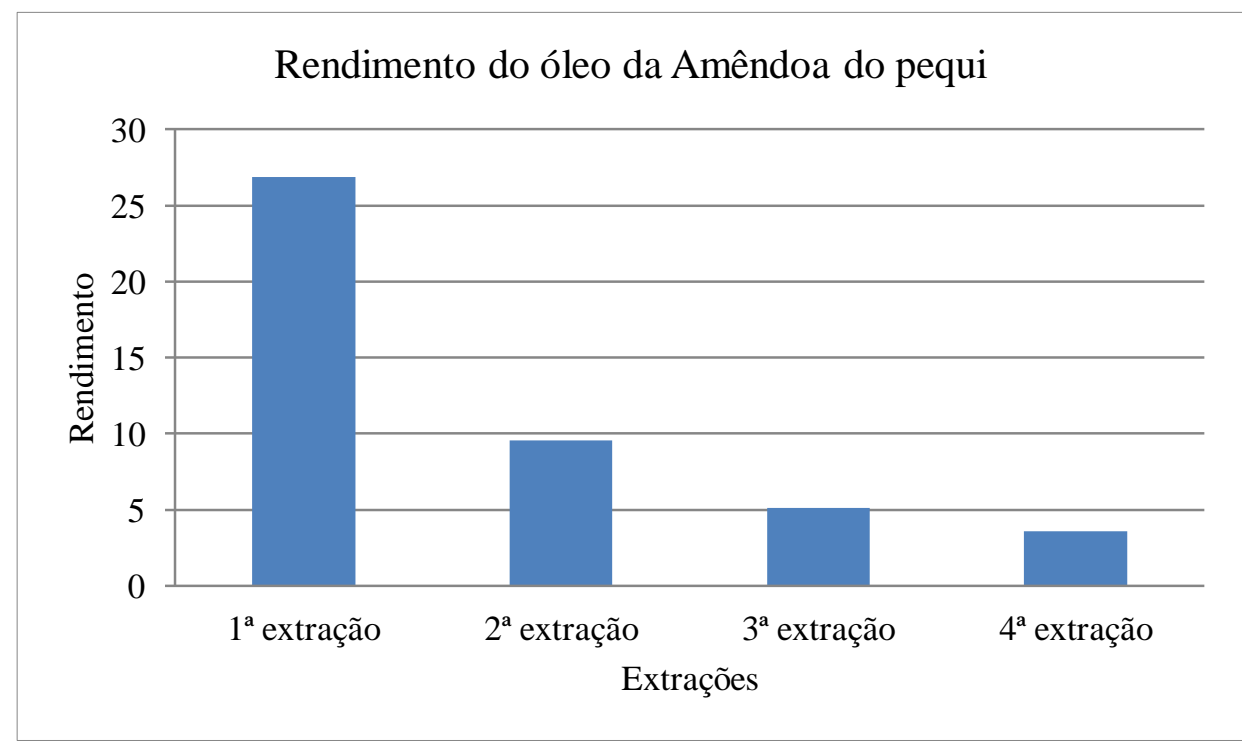

Figura 2 - Rendimento do óleo da amêndoa do pequi.

\section{Conclusão}

A análise dos resultados obtidos mostrou que, a reutilização do pequi na extração do óleo, só será tecnicamente viável se apenas um reciclo for realizado, tendo em vista que a partir da terceira extração da mesma amostra o rendimento do óleo extraído cai para valores abaixo de $10 \%$.

\section{Bibliografia}

ARAÚJO, Jéssica Pessoa. Estudo da influência da temperatura e razão molar na extração do óleo de pequi (Caryocar brasiliense) através do método sonoquímico.2013. 45f. Monografia (Bacharelado em Ciência e Tecnologia) Universidade Federal Rural do Semiárido, Mossoró-RN, 2013.

BARBALHO, Thales Cainã Dos Santos. Estudo da Extração do Óleo de Pequi (Caryocar Brasilienses Camb.) Assistida por Ultrassom. 2012. $50 \mathrm{f}$. Monografia (Bacharelado em Ciência e Tecnologia) - Universidade Federal Rural do Semi-Árido, Mossoró-RN, 2012.

BRANDÃO, M. et al,. Árvores Nativas e Exóticas do Estado de Minas Gerais. Belo Horizonte: EPAMIG, 2002. 528 p. 
DANTAS, Danielli Matias M. et al. Extração de óleo de mocri alga utilizando ultrassom com diferentes solventes visando a produção de biodiesel. In: Congresso Brasileiro de Mamona, 4 , 2010, João Pessoa. Anais... Recife: UFPE, 2010.

DEUS, Tatiana Nogueira de. Extração e Caracterização de Óleo do Pequi (Caryocar brasiliensisCamb.) Para o Uso Sustentável em Formulações Cosméticas Óleo/Água (O/A). 2008. 75 f. Dissertação (Mestrado) - Unicag, Goiânia, 2008.

FIGUEIREDO, Pablo Marciano da Silva. Estudo da Extração do Óleo da Borra de Café para a Produção de Biodiesel. 2011. 52 f. Monografia (Graduado) - UFERSA, Mossoró, 2011.

SGANZERLA, Marla et al. Extração de óleo das amêndoas de frutos de butiá (Butiacapitata e Butiaeriosphata) por três diferentes métodos. In: Congresso de Iniciação Científica, 18 , 2009, Pelotas. Anais... Pelotas: UFPel, 2009.

LORENZI, H. Árvores brasileiras: manual de identificação e cultivo de plantas arbóreasnativas do Brasil. Nova Odessa: Plantarum, 2000.

MARIANO, Renata Gomes de Brito. Extração do Óleo da Polpa de Pequi (Caryocar Brasiliense) por Processos Convencionais com Processos Convencionais Combinados com Tecnologia Enzimática. Instituto de Tecnologia. Programa de PósGraduação em Ciência e Tecnologia de Alimentos. Universidade Federal Rural do Rio de Janeiro, Seropédica, RJ, p.18-20, 2008

MATOS, L. J. B .L.et al.,.Extração do óleo da borra de café assistido por ultrassom visando a produção de biodiesel. Fortaleza: 2009.

RIBEIRO, A. E. O espaço, o homem e o seu destino no norte de Minas. In: UNIVERSIDADE FEDERAL DE LAVRAS. Departamento de Administração e Economia. Manejo sustentado do cerrado para uso múltiplo: subprojeto agroecologia e desenvolvimento. Lavras, 1996. p.11-18. 